\title{
Prescription of oxygen concentrators: adherence to published guidelines
}

\author{
J P DILWORTH, C M B HIGGS, P A JONES, R J WHITE \\ From Frenchay Hospital, Bristol, and Royal United Hospital, Bath
}

ABSTRACT The indications for the prescription of oxygen concentrators have been assessed in $82 \times$ patients against the Department of Health guidelines, except that only one set of blood gas and spirometry measurements was required if the patient's condition was stable. Of the 49 patients recommended for this treatment by a chest physician, $41(82 \%)$ fulfilled the requirements, compared $\partial$ with only 11 of 33 patients where the concentrator was recommended by a general practitioner or 0 non-specialist physician. Eleven patients died within one month of prescription. The results show that many patients are being prescribed oxygen concentrators without assessment and underline the $\subseteq$ importance of full assessment and attention to prognosis before prescription.

\section{Introduction}

Long term oxygen therapy given for 15 hours a day or more has been shown to improve prognosis in certain patients with chronic hypoxaemia. ${ }^{12}$ The oxygen concentrator is a convenient method of delivering this treatment. In England and Wales it is cheaper to prescribe concentrators than cylinders if oxygen is to be administered for more than eight hours a day. Concentrators have been available by prescription under the National Health Service since November 1985. The Department of Health and Social Security published guidelines that define circumstances in which prescription of a concentrator is appropriate (table 1). This study was designed to assess whether the Department of Health guidelines are being met.

\section{Methods}

We reviewed all prescriptions for oxygen concentrators issued from 1 December 1985 to 31 December 1987 in two adjacent health districts in Avon (population 623000 ) with a mixed urban and rural population. This was achieved by retrospective review of the case notes of patients where the recommendation came from a hospital specialist and by individual contact and by discussion with the general practitioner in cases where the recommendation was made without

Address for reprint requests: Dr J P Dilworth, Department of Medicine, Frenchay Hospital, Bristol BS16 1LE.

Accepted 12 April 1989 hospital referral. Names of patients were obtained with the help of a list provided by the local family practitioner committee, which sought the consent of individual general practitioners. Approval by the chairman of the Frenchay district ethical committee was obtained. The Department of Health guidelines (table 1) were interpreted in this study as requiring only one set of appropriate blood gas measurements and spirometry in the stable state because of patients' reluctance to attend on two occasions; hospital physicians said that blood gas tensions were checked twice if there was doubt over stability.

\section{Results}

Eighty four concentrators were prescribed during the study period, of which two were for children and are

Table 1 Department of Health guidelines for prescribing long term oxygen

Absolute indication

Chronic obstructive airways disease

hypoxaemia $\left(\mathrm{Po}_{2}<55 \mathrm{~mm} \mathrm{Hg}\right)$, hypercapnia

$\left(\mathrm{PCO}_{2}>45 \mathrm{~mm} \mathrm{Hg}\right)$, oedema, FEV $1<1.51$, and FVC $<2.01$ in the stable phase more than three weeks from an exacerbation, repeated after three weeks with a variation of $<5 \mathrm{~mm} \mathrm{Hg}$ in $\mathrm{Po}_{2}$ and $<20 \%$ in spirometric measurements

Other indications

Chronic obstructive airways disease with hypoxaemia but without hypercapnia or oedema

Palliative - that is, other respiratory conditions with hypoxaemia (for example, fibrosis)

Frequent cylinder replacement: more than 21 cylinders a month or more than eight hours a day

$\mathrm{Po}_{2}$-oxygen tension; $\mathrm{PCO}_{2}-$ carbon dioxide tension; $\mathrm{FEV}_{1}$-forced expiratory volume in one second; $\mathrm{FVC}$ - forced vital capacity. $1 \mathrm{~mm} \mathrm{Hg} \approx 0.13 \mathrm{kPa}$. 
excluded from the analysis. There were 56 male and 26 female patients with an age range of 42-86 (mean 71) years. The diagnoses at the time of recommendation were cor pulmonale (44 patients), chronic obstructive airways disease without cor pulmonale (23), fibrosing alveolitis (7), and carcinoma (3), five being unknown.

Eleven concentrators were prescribed in December 1985 but since then the rate of prescription has remained unchanged at about three a month. Thirty five patients had died by the end of December 1987, 18 within three months of prescription. Eleven patients died within the first month, of whom six had not been assessed appropriately. No difference was noted in the degree of hypoxaemia or hypercapnia between those patients who died within one month and those who survived longer, though the number in the former group who had had blood gas analysis was too small for statistical analysis.

There were 49 recommendations from consultants with a specialist interest in chest medicine, 29 from general practitioners, and four from other hospital based physicians. Of the 49 patients for whom oxygen was recommended by consultants, 34 had cor pulmonale, nine chronic obstructive lung disease, and six pulmonary fibrosis. Forty one of the 49 patients $(81 \%)$ fulfilled the criteria for prescription, most (36 patients) for hypoxaemia (table 2). Six patients were not assessed when stable and two were not assessed at all. Three of these six patients died within one week of prescription. In the 41 patients assessed adequately only one died in the first week.

Of the 33 patients for whom oxygen was recommended by general practitioners or non-specialist physicians, nine had cor pulmonale, 15 chronic obstructive lung disease, one pulmonary fibrosis, and three carcinoma; in five the diagnosis was unknown. Twenty seven of the 33 patients $(81 \%)$ were not investigated (table 3); only one fulfilled the Department of Health guidelines for hypoxaemia. Ten concentrators were prescribed to replace oxygen cylinders for patients requiring oxygen for over eight hours a day and these prescriptions were therefore within the spirit of the guidelines. Five concentrators, however,

Table 2 Chest consultants' recommendations

\begin{tabular}{ll}
\hline & $\begin{array}{l}\text { No (\%) } \\
\text { of } \\
\text { patients }\end{array}$ \\
\hline Fulfilled guidelines & $41(85)$ \\
Chronic obstructive airways disease with & 23 \\
hypoxaemia, hypercapnia, and oedema & 7 \\
Chronic obstructive airways disease with hypoxaemia & 6 \\
Fibrosis with hypoxaemia & 5 \\
Appropriate replacement of cylinders & $8(15)$ \\
Did not fulfil guidelines & 6 \\
Assessment within three weeks of an & 2 \\
acute exacerbation & \\
Not investigated & \\
\hline
\end{tabular}

Table 3 General practitioner and non-specialist physicians' recommendations

\begin{tabular}{ll}
\hline & $\begin{array}{l}\text { No }(\%) \\
\text { of } \\
\text { patients }\end{array}$ \\
\hline $\begin{array}{l}\text { Fulfilled guidelines } \\
\text { Hospital assessment by non-specialist physician } \\
\text { Appropriate replacement of oxygen cylinders }\end{array}$ & $11(33)$ \\
$\begin{array}{l}\text { Did not fulfil guidelines } \\
\text { Incomplete hospital assessment by non-specialist } \\
\text { physicians }\end{array}$ & 10 \\
$\begin{array}{l}\text { Installed before hospital assessment and then } \\
\text { removed }\end{array}$ & $22(67)$ \\
$\begin{array}{l}\text { Against consultant advice } \\
\text { Not investigated }\end{array}$ & 1 \\
\hline
\end{tabular}

were subsequently removed because they were underused.

\section{Discussion}

The advent of the oxygen concentrator has made the prescription of long term oxygen more convenient and potentially less expensive. A concentrator is appropriately prescribed for treatment of defined patients with cor pulmonale to improve prognosis. ${ }^{2}$ Symptomatic treatment in other patients when required for more than eight hours a day is also acceptable according to the Department of Health guidelines, though we consider that these patients should be assessed by a specialist physician.

Of the 82 patients reviewed, $29(35 \%)$ received a concentrator without hospital referral. Forty nine patients were recommended concentrators by chest physicians, of whom $41(85 \%)$ were assessed according to the Department of Health guidelines and fulfilled the criteria for prescription, with the exception of repeat assessment in the stable state. Nineteen patients $(66 \%)$ recommended for a concentrator by a general practitioner, eight $(16 \%)$ recommended by a chest physician, and three of four recommended by a nonspecialist physician did not have their concentrator prescribed in accordance with the guidelines.

Several areas of concern have been identified. Firstly, concentrators were installed without any assessment in one third of cases. We cannot comment on whether the criteria would have been met in these patients. Some patients refused assessment and several general practitioners were under the impression that admission overnight would be necessary and were therefore unhappy about referral. They also expressed concern over a possible delay in the assessment. In addition some patients are never truly "stable." Secondly, some patients were not assessed according to the guidelines. Of the six not assessed in the stable state, three died shortly after installation of the concentrator and would have been treated more 
appropriately with oxygen cylinders. This emphasises the importance of delaying assessment at least three weeks after an exacerbation.

Possibly the guidelines are too strict and other patients would benefit from long term oxygen therapy; but until we have evidence that this is so long term oxygen therapy should be confined to those cases where there is proved benefit. The current guidelines offer sufficient flexibility to the prescribing physician to permit the prescription of concentrators for palliative treatment where this is indicated. This study emphasises the importance of referral for full assess- ment and the need for a specialist to be in a position to make these assessments without delay.

\section{References}

1 Nocturnal Oxygen Therapy Trial Group. Continuous or nocturnal oxygen therapy in hypoxaemic chronic obstructive airways disease: a clinical trial. Ann Intern of Med 1980;93:391-8.

2 Medical Research Council Working Party. Long term domiciliary oxygen therapy in chronic hypoxaemic cor pulmonale complicating chronic bronchitis and emphysema. Lancet 1981;i:681-5. 